\title{
NUCLEAR PLANT SAFETY AND IT'S ENVIRONMENTAL IMPACT
}

\author{
Siddharth Roy \\ UG Scholar, \\ Department of Electrical Engineering \\ Bharati Vidyapeeth Deemed University, \\ College of Engineering, \\ Pune, India
}

\begin{abstract}
Power is a supply on which civil society is developed. It affects every aspect of life and is energetic to the being of the current world. This paper explains the effects it has on a national and global scale. A projected technology for the progress of nuclear energy is also inspected to show its aids and compare it to conventional nuclear energy. In India Nuclear power plants secure the fourth place in terms of producing electricity. the civil society is totally built on the resources of electricity. This paper discovers nuclear power and its presence it throws on the globe. Both the positive and negative respects of the Nuclear power plant are taken under consideration while writing this paper. The paper also contains the better way and modification on of Nuclear power plant that makes it better than other conventional sources in several aspects. The review is collected from an extensive variety of writers, experts and nuclear doyens.
\end{abstract}

Keywords: Nuclear power, Nuclear Reactors, Electricity, Nuclear power Plants.

\section{INTRODUCTION}

The Nuclear power plant is a thermal station in which Nuclear reactor serves as the main source of heat. The heat is used inside the Heat exchanger to heat up the water into very high temperature of steam. The turbine is rotated by injecting a high pressurized steam over its blade which rotates, and the turbine is attached with and electrical generator which moves the shaft. The shaft acts as a prime mover to the generator, and the mechanical energy is converted to electrical energy. Hence electricity is produced (Diecxamp, et al, 1971).

On September $3^{\text {rd }} 1948$, Tennessee in the United States, was the first to generate electricity using nuclear reactor at the X-10 Graphite reactor in Oak Ridge. The X-10 Graphite reactor was also the first nuclear power plant which powered a light bulb (Kenward, 1976).

The Nuclear power plant has also a very hazardous impact on the environment because of the Nuclear fuel. As the waste generated in a Nuclear power

\author{
V.V Mehtre \\ Assistant Professor, \\ Department of Electrical Engineering, \\ Bharati Vidyapeeth Deemed University, \\ College of Engineering, \\ Pune, India
}

plants are very radioactive in nature which may lead to very serious damage to mankind as well as animals (Energy Prospects to 1985, Paris (1974)). The waste of Nuclear power plants is also dangerous to marine creatures as the waste results in water poisoning (Masters, GM, London (1975).

\section{NUCLEAR POWER PLANT}

The Nuclear power plant is much similar to that of a thermal power station as in this also the generation of electricity goes indirectly. In Nuclear power plant the reactor liquid is heated up by the Nuclear reactor (HANSEN, M, 1976). The liquid can be anything depending upon the type and quality of the boiler or reactor. In the reactor the coolant is heated to generate steam which is fed to the steam turbine. After which the steam or the remaining steam is driven in a condenser which condenses the steam (BLOMEKE, 1975).

The condenser acts as a heat exchanger which cools the steam and then it is further connected into river for disposal or a cooling tower. The cooling tower then cools the steam to water and again the water is pumped back to the steam generator and the process continues (Diecxamp, et al,1971).

The diagram is shown in Fig 1.

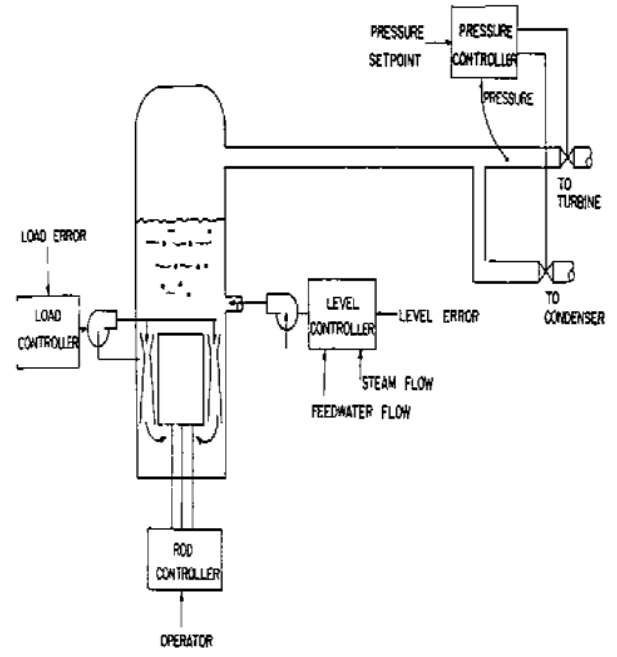

Fig 1: Boiling Water Reactor System in nuclear power plant 


\section{PARTS OF NUCLEAR POWER PLANT}

1) Fuel

The material which undergoes fission is called fuel or nuclear fuel. The mainly and the most feasible fuels are Plutonium (Pu-236), Uranium (U-238) and Thorium (Th-232). And among all these Uranium is the most preferred because of its high melting point(KENDALL, et al. Sievvrra Club (1974)).

2) Moderator

They are simple rods used to control the chain reaction by absorbing the energy and slowing down the speed of the neutrons. The chain reaction is controlled by the neutrons which have the desired speed.

There are certain elements like Boron, Cadmium, Silver, Indium etc. are the most commonly used elements in the control chain reaction. As they have the tendency of absorbing vast number of neutrons without involving themselves into the fission reaction (Biello, D. 2012, March 18).

\section{3) Coolant}

Because of decay heat Nuclear fuels requires continuous heating no matter if the reactor is operating or not. Fuel cooling consists of three systems:

i.

\section{Heating transport system-}

The heating transport system brings the heat produced by the Nuclear reactor to the steam generators. This system is made up of very robust pipes filled with heavy water(BAIR, R C .Science 183 (1974) 715).

\section{ii. Steam systems}

The condensation system uses regular water, the heat from the reactor turns this water into high pressure steam for the rotation of turbines and generators. That steam is then cooled and condensed using the third system that pumps in cold water from a body of water such as a lake or reservoir (Biello, D. 2012, March 18).

\section{4) Control Rods}

These rods are implemented in the Nuclear power station so as to control the speed of fission of the radioactive fuel. The basic elements used to make a control rods are Boron (B-10), Cadmium (Cd-113), Silver (Ag), Hafnium (Hf) etc. Here as we know that Boron (B-10) has the great tendency to absorb neutrons but, being brittle in nature Boron are not so desirable for constructing a control rod (Kenward, M 1976).

But Hafnium (Hf) owns a good mechanical property which makes it unique and a control rod can be constructed using Hafnium without the mixture of any other metal (Energy Prospects to 1985 Paris 1974).

5) Turbines-

The turbine consists of fins on which the highpressure steams are injected. The turbine rotates because of the force of the high pressurized steam. Now, the turbine rotates converting the heat energy to mechanical energy further coupling with the generator (Power Reactor in Member states Vienna, 1976).

\section{6) Generator-}

The generator is coupled with the turbine and as a result the moving turbine and the change in the magnetic flux causes the production of electricity. The generators used are of low-pole $\mathrm{AC}$ synchronous type and are rated at high speed (HANSEN, M, 1976).

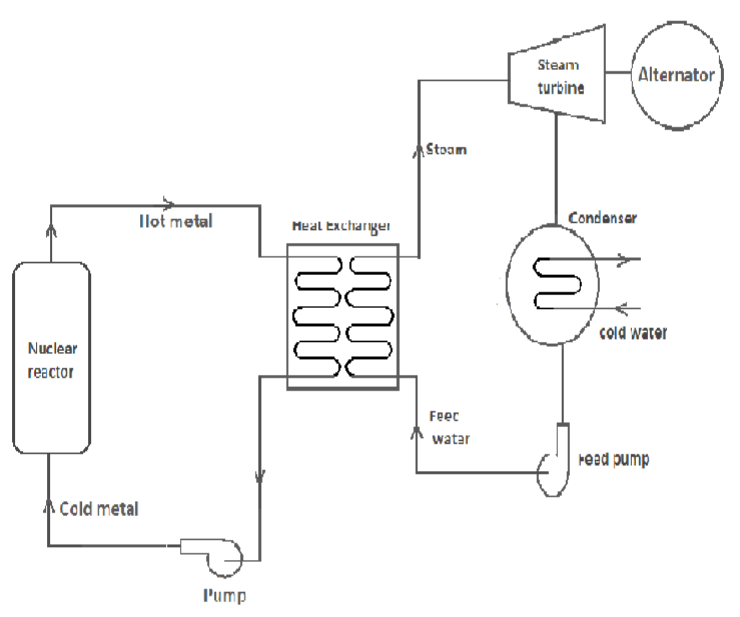

Fig 2: Block diagram of Nuclear power plant

\section{PROPOSED IDEAS}

\section{Automatic Control Rods-}

If we set the control rods to work automatically then several disasters such as the Chernobyl can be prevented. While functioning automatically the machine will take care of the temperature, pressure and the power of fission reaction inside the reactor. The automatic control rods will also help in stopping the fission reaction completely inside the reactor by submerging itself completely in case of emergency. It will also reduce the complexity in the routine maintenance hours. In accumulation to these structures, there are protection arrangements as well as Alarm and one-to-one care arrangements. Maximum of the NPPs will have the ultimate trip logics as well as safety arrangement firm reinforced. They are programmed but not grounded on any software-based arrangements. Recent NPPs do have computerised SCADA systems with Event and data logging for operative evidence, display, trending and 


\section{International Journal of Engineering Applied Sciences and Technology, 2020 Vol. 4, Issue 12, ISSN No. 2455-2143, Pages 287-289 \\ Published Online April 2020 in IJEAST (http://www.ijeast.com)}

analysis purpose. However, all the vital parameters will also be panel displayed. All the vital sensor channels are usually triplicated (with either median or 2 out of 3 logic). Pressurized Heavy Water Reactors (PHWRs) need daily re-fuelling. This is carried out on power, without shutting the reactor down. This complex activity is achieved entirely by remote control. Computes control the fuelling machines that pushes out old fuel and loads new fuel into the Reactor. Old fuel is also sent to the storage remotely.

\section{NUCLEAR BENEFITS}

The Nuclear power has a very vast benefits to the world. First of all, it has very few emissions as compared to any other conventional type of power plants. The conventional power plants use fossil fuel for their electricity generation such as coal. The burning of coal contributes a very vast rise in environment pollution ((BIER Report) (1974)).

As also the intake is very low for such a high-power generation and the emission is also not contributing in any greenhouse effect or any climate change as there is no such emission of gases (Diecxamp, et al, 1971). The fossil fuels or the oils are on the verge of extinction so as a result for a very good efficiency power plat we can use Nuclear power plant (USAEC, WASH-1400, 1974).

\section{THREATS IN NUCLEAR POWER PLANT}

There are many serious threats in Nuclear power plant, mainly inside the reactor as there are very dangerous radioactive fission reaction going inside the Nuclear reactor. Due to the emission of such vast energy the temperature of the reactor rises very massively and can lead to bursting of the reactor if the control rods failed to work for stopping of the fission reaction. And if the reactor bursts it will emit a very high dangerous radioactive radiations, which will result in loss of life and will result in a very terrifying disaster (BLOMEKE, JO, 1975).

\section{ENVIROMENTAL IMPACTS}

The waste disposed from the Nuclear power plants are very radioactive in nature. So, before the disposal they should be treated with appropriate elements or with some other radioactive disposing materials. The waste leaves a very harsh impact on the surrounding environments (like Plants, Animals and Human Beings) because the radioactive emitted from the waste take more than 1000 years to stop such radioactive emission (Dinar et al, 2012, October 18). So, this trapping of radiations for over 1000 of years can lead to serious harms to the surrounding as well as mankind and other living creatures (Friedberg, et al. 2008).

\section{CONCLUSION}

There are several types of electricity generation plant. We have covered all the advantages and disadvantages of Nuclear power plant over various types of conventional power plants. After comparing with all of the power plants and in all aspects. It seems that the Nuclear power plant provides the energy in less fuel as well as with higher efficiency (Biello, D., 2012, March 18). So, if the solution of its waste handling is somehow taken out it will be the best electricity generating plant with the least amount of emissions.

\section{ACKNOWEDGEMENT}

I would like to express my special thanks of gratitude to my subject teacher Mr. Swapnil Namekar for their able guidance and support in completing my research paper. I would also like to extend my gratitude towards our head of the department "Mr. D.S. Bankar" and our senior faculty member "Mr. V.V MEHTRE" for providing me with all the facilities that were required.

\section{REFERENCE}

[1.] Energy Prospects to 1985, OECD”, Paris (1974).

[2.] Power Reactor in Member states "INTERNATIONALATOMIC ENERGY AGENCY”,IAEA, Vienna (1976).

[3.] Kenward, " AEA Bulletin" (1976).

[4.] HANSEN, M, “IAEA Bulletin” (1976).

[5.] Diecxamp, H, Trans Am. "Geophys union" (1971).

[6.] (BIER Report) "National Academy of Science, the effects on Populations of exposure to low levels of ionizing radiations Washington" (1974).

[7.] Masters, GM, "Introduction to Environmental science and Technology”, Wiley, London (1975).

[8.] USAEC,WASH-1400 “Rasmussen Report”, (1974).

[9.] KENDALL, HW, MUGLEWER, S, "Preliminary Review of the AEC Reactor Safety Study”, Sievvrra Club (1974).

[10.] BAIR, J W., THOMPSON, R C .Science 183 (1974) 715.

[11.] Biello, D. Small reactors make a bid to revive nuclear power (2012, March 27)

[12.] Shlomi Dinar, Lucia De Stefano, James Duncan, Kerstin Stahl, "No wars for water"'(October 18, 2012).

[13.] Friedberg \& Schoenfeil, G. "The danger of a diminished America” (2008). 